\title{
Volumetric Analysis and Performance of Hot Mix Asphalt with Variable Rap Content
}

\author{
Ahmad Kamil Arshad, ,2, , Masyita Mohammad ${ }^{2}$, Ekarizan Shaffie ${ }^{2}$, Wardati Hashim ${ }^{2}$, \\ and $A$. G. Abdul Halim ${ }^{3}$ \\ ${ }^{1}$ Institute for Infrastructure Engineering and Sustainability Management (IIESM), Universiti \\ Teknologi MARA, Shah Alam, Selangor, Malaysia \\ ${ }^{2}$ Faculty of Civil Engineering, Universiti Teknologi MARA, Shah Alam, Selangor, Malaysia \\ ${ }^{3}$ Faculty of Civil and Environmental Engineering, Universiti Tun Hussein Onn, Malaysia
}

\begin{abstract}
Incorporating Reclaimed Asphalt Pavement (RAP) to the asphalt concrete mixture for highway construction offer many benefits including energy consumption, conservation of natural resources and preservation of the environment to associated emissions. This paper presents a study on performance of Hot Mix Asphalt with variable RAP content. The study is carried out to evaluate the Marshall Properties and Performance of RAP-Asphalt mixes using conventional asphaltic concrete mix AC14. Marshall Mix Design Method was used to produce control mix ( $0 \%$ RAP) and RAP-Asphalt mixes samples which consist of $15 \%$ RAP, $25 \%$ RAP and 35\% RAP in accordance with Specifications for Road Works of Public Works Department, Malaysia. The Marshall Properties analysis was performed to ensure compliance with Marshall Requirements, The resilient modulus test was performed to measure the stiffness of the mixes while Modified Lottman test was conducted to evaluate the moisture susceptibility of these mixes. The results obtained showed that there were no substantial difference in Marshall Properties, moisture susceptibility and indirect tensile strength between RAP-Asphalt mixes with the control mix. The test results indicated that recycled mixes performed as good as the performance of conventional HMA in terms of moisture susceptibility and resilient modulus. It is recommended that further research be carried out for asphalt mixes containing more than $35 \%$ of RAP material.
\end{abstract}

\section{Introduction}

Hot Mix Asphalt (HMA) is a dense graded mix that is commonly used as road surfacing intended for general use. If HMA is properly designed, it will provide impermeable characteristic which allow the water to run away from the pavement's surface. However, over time, pavement distresses inhibit the optimal function of roads and contribute to traffic accident. Damaged pavements are considered one of the largest contributing factors to fatal motor vehicle crashes [1]. Therefore, there is a need to rehabilitate the pavement and in most cases, remove the asphalt surfacing material to be replaced by a new asphalt overlay.

* Corresponding author: drahmadkamil@salam.uitm.edu.my 
Approximately about $80 \%$ of asphalt pavement removed during highway rehabilitation or reconstruction is recycled back into new hot mix asphalt (HMA), disposing of only $20 \%$ through normal waste stream channels [2]. Recycling of asphalt pavement is an alternative technology developed to rehabilitate and or replace pavement structure suffering from pavement deformation and structural damage. However, although recycling is beneficial in most cases by reducing the consumption of virgin materials, the performance of the highway pavement should not be compromised for cost reduction [3]. It has been accepted that RAP can be a feasible constituent in HMA pavements and if properly designed and constructed, HMA mixtures with RAP can perform as well as conventional mixtures [4]. Some studies indicates that incorporating low percentages of RAP (up to 15\% RAP) have no significant changes in the performances of mixes [5].

Studies in Europe and the United States have concluded that over $80 \%$ of the recycled material is reused in the construction of roads, but regulations are still strict in allowing the inclusion of RAP in proportions ranging between 5 and 50\% for production of new HMA mixtures [6]. Previous researchers stated that RAP replacement at proportions below $50 \%$ is feasible to produce new HMA mixtures, obtaining satisfactory results in the mechanical properties. Likewise, the susceptibility to moisture damage was low with the Tensile Strength Ratio (TSR) values close to 95\%[7][8]. In addition, the HMA mixtures with RAP replacement increased in 50\% the Indirect Tensile Strength (ITS) compared to the HMA mixtures with only virgin materials [9].

In addition, RAP replacement at proportions above $50 \%$ is feasible to produce new HMA mixtures, obtaining satisfactory results in the mechanical properties [10]. Partial blending of RAP binder occurs in the hot mix asphalt when RAP is mixed with virgin mineral materials and virgin binder. The amount of RAP has been limited to certain portion because the degree of blending between the RAP and the virgin materials is not known. If the weight by percent of all materials and their recycling technology are properly selected, the composition and properties of RAP HMA are improved.

Research on pavement recycling and RAP asphalt mixtures in Malaysia is very limited. Few research have been carried out on mixes containing RAP exceeding $25 \%$ as higher amount of RAP produced variability in Marshall Properties and performance of HMA. The objective of this study is to evaluate the performance of HMA mixtures with variable RAP content $(15 \%, 25 \%$ and $35 \%$ RAP), in particular the Marshall properties and performance in terms of resilient modulus and moisture susceptibility.

\section{Methodology}

This study is based on laboratory experimental work. The samples were prepared using the Marshall Test method in accordance with ASTM D1559. The mix design used AC14 aggregate gradation in accordance with PWD Malaysia's Specification for Road Works [11], with the range of binder content from $4.0 \%$ to $6.0 \%$. A total of 15 samples were prepared for the control mix (100\% virgin aggregates) and the asphaltic concrete mixes with RAP contents of $15 \%, 25 \%$ and $35 \%$. All the samples were compacted with 75 blows on both sides of the samples using Marshall Compactor. Volumetric properties and analysis were carried out to determine the optimum binder content (OBC) for control mix and recycled mix. The optimum bitumen content value was used for the performance tests including resilient modulus and moisture susceptibility. Moisture susceptibility test was performed in accordance to the procedure described in AASHTO T 283. Samples for the test were prepared at $7+0.5$ percent air voids. Resilient modulus test was performed in accordance to ASTM D 4132. Testing temperatures of 25 and $35^{\circ} \mathrm{C}$ were used and loading of $1300 \mathrm{~N}$ with load pulse of 0.1 seconds and rest period of 0.9 seconds were set. 


\section{Result and discussion}

The initial laboratory tests have been conducted to determine physical properties of the materials used. marshall mix design was conducted to determine the marshall properties and the optimum binder content (obc) for control mix and rap-asphalt mixes. the results of moisture susceptibility test and resilient modulus test as performance tests were then compared between the control mix and rap mixes.

\subsection{Comparison of RAP aggregate and virgin aggregate properties}

RAP aggregate properties assist in evaluating the suitability of the aggregates to be used in road construction. The basic properties tests that were conducted for both virgin and RAP aggregates consist of Los Angeles abrasion test, aggregate impact test and specific gravity. The detailed test results for both types of aggregate are shown in Table 1.

For this study, based on the results as shown in Table 1, the LAAV, AIV, Specific Gravity for RAP aggregate is higher than virgin aggregate. This indicates that the strength of the recycled aggregate is lower than virgin aggregate. However, the value complied with PWD Malaysia's specification requirements which must not exceed 25\% for LAAV and AIV. This is due to the fact that the recycled aggregate was exposed to traffic loading for a long period that reduced the strength of aggregate, unlike the virgin aggregate which has not been exposed to traffic. Since both types of aggregate complied with the specification requirements, the aggregate is suitable to be used for the asphalt mixtures preparation.

Table 1. Basic properties of virgin aggregate and RAP aggregate

\begin{tabular}{|c|c|c|c|}
\hline Parameter & $\begin{array}{c}\text { Virgin } \\
\text { Aggregate }\end{array}$ & $\begin{array}{c}\text { Reclaimed } \\
\text { Asphalt } \\
\text { Aggregate } \\
\text { (RAP) }\end{array}$ & $\begin{array}{c}\text { PWD } \\
\text { Malaysia's } \\
\text { Specification } \\
\text { requirement }\end{array}$ \\
\hline Los Angeles Abrasion Value (\%) & 24.00 & 24.91 & $<25$ \\
\hline Aggregate Impact Value (\%) & 14.99 & 19.98 & $<25$ \\
\hline Bulk Specific Gravity, Gsb $\left(\mathrm{g} / \mathrm{cm}^{3}\right)$ & 2.648 & 2.625 & - \\
\hline Apparent Specific Gravity $\left(\mathrm{g} / \mathrm{cm}^{3}\right)$ & 2.705 & 2.711 & - \\
\hline Water Absorption (\%) & 0.626 & 1.063 & $<2.0$ \\
\hline
\end{tabular}

\subsection{Marshall properties}

Marshall Test was conducted to determine the volumetric properties of mixture. The volumetric properties determined included bulk specific gravity, air void, voids in mix (VMA), stability and flow. The Optimum Binder Content (OBC) for the control and RAPAsphalt mixes were determined from the individual plots of bulk density, voids in total mix, voids in mix, flow and stability versus percent asphalt content.

Mix properties for virgin materials and varying different percentage of RAP showed that there are significant effect on the Marshall Properties with the inclusion of RAP in the asphalt mixes. Marshall Test result showed that the Marshall flow, VFB and Bulk SG increased as the RAP content increased. However, Marshall Stability value and voids in mix showed a decreasing trend with increasing RAP content. The trends are shown in Fig. 1 to Fig. 5 below. This result could be attributed to the fact that the virgin bitumen failed to rejuvenate the RAP binder as its percentage increases. However, the results and analysis showed that there is not much variation between conventional mixes with RAP-Asphalt mixes and all the mixes satisfy the requirements of the Specifications for Marshall Test. 


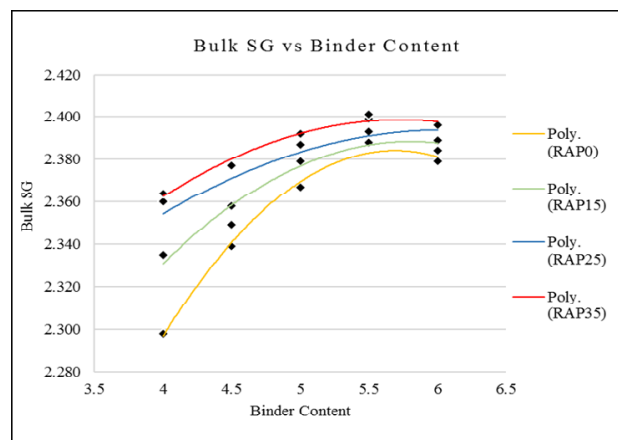

Fig. 1. Bulk specific gravity versus binder content for different RAP contents

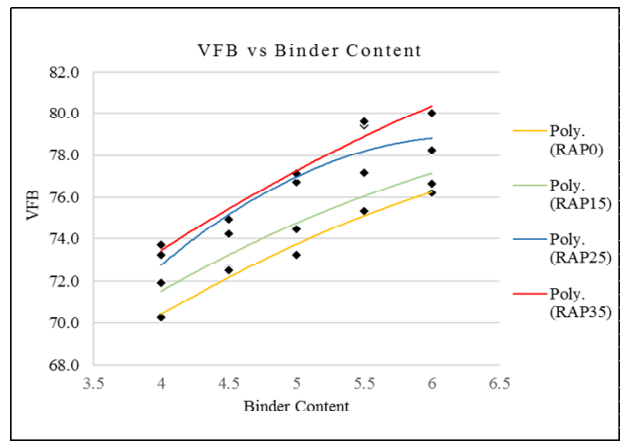

Fig. 3. VFB versus binder content for different RAP contents

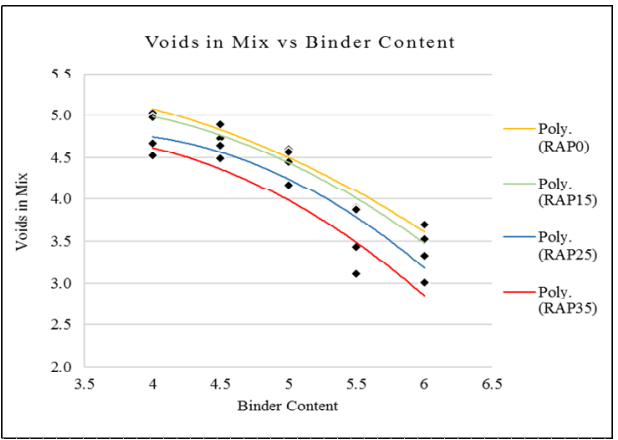

Fig. 2. Voids in mix versus binder content for different RAP contents

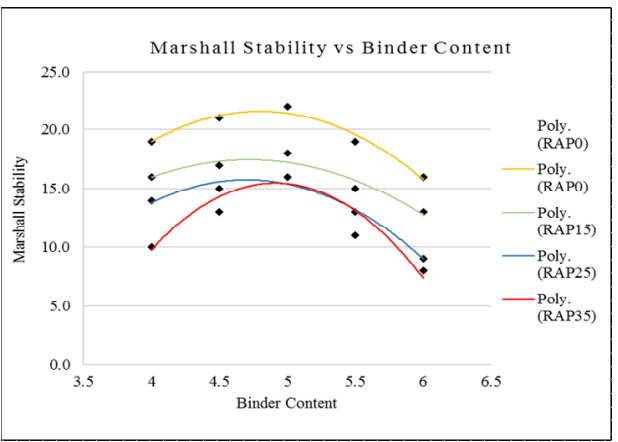

Fig. 4. Marshall stability versus binder content for different RAP contents

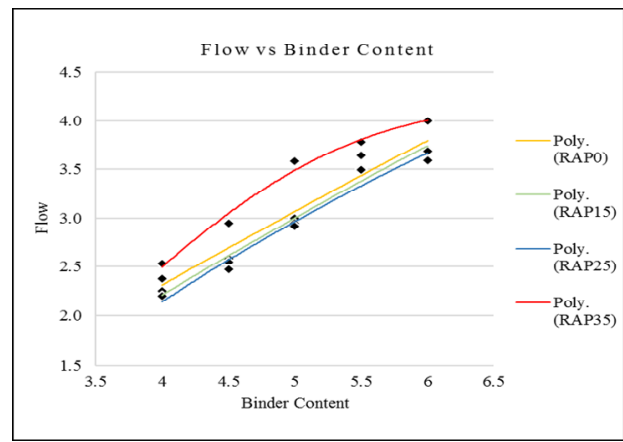

Fig. 5. Flow versus binder content for different RAP contents

\subsection{Marshall properties and determination of optimum binder content}

The OBC for control mix and RAP-Asphalt mixes were taken as the arithmetic mean of binder from the five smooth curves plotted and the value was checked with the limits set in Public Works Department specification. Table 2 showed the Optimum Binder Content (OBC) for the control and RAP-Asphalt mixes. The OBC decreased as the RAP content increased. The OBC for control mix, RAP15 and RAP25 and RAP35 are 5.34 \%, $5.22 \%$, 
$5.10 \%$ and $4.88 \%$ respectively. The result obtained showed that there were no substantial differences in Marshall Properties.

Table 2. Mix Design selection criteria

\begin{tabular}{|c|c|c|c|c|c|}
\hline Properties & $\begin{array}{c}\text { Control } \\
\text { Mix }\end{array}$ & RAP15 & RAP25 & RAP35 & $\begin{array}{c}\text { PWD } \\
\text { Specification }\end{array}$ \\
\hline OBC (\%) & 5.34 & 5.22 & 5.10 & 4.88 & - \\
\hline Bulk S.G & 2.388 & 2.393 & 2.399 & 2.401 & - \\
\hline VIM (\%) & 4 & 4 & 4 & 4 & $3-5$ \\
\hline VFB (\%) & 75.33 & 75.20 & 75.20 & 75.10 & $70-80$ \\
\hline Stability (kN) & 22 & 18 & 16 & 18 & $>8$ \\
\hline Flow (mm) & 3 & 2.95 & 2.92 & 2.95 & $2-4$ \\
\hline
\end{tabular}

\subsection{Indirect tensile strength}

The results of indirect tensile strength (ITS) for control mix and RAP-Asphalt mixes are shown in Fig. 7. It is noticed that the increase of RAP in the asphalt mix reduces the tensile strength values compared with the control mix. The results shows that the ITS values of wet condition and dry condition decreased with increasing RAP content. The graph's trend showed that the use of relatively higher RAP content reduces the moisture resistance. Since RAP aggregate is weaker compared to virgin aggregate, some particles could have been crushed during the compaction and fractured surface is exposed to water. Good quality aggregate is important to reduce the moisture damage in mix. The values of Control Sample, RAP15, RAP25 and RAP35 reduced by $4.29 \%, 12.16 \%, 16.13 \%$, and $20.0 \%$ respectively, after the wet conditioning process. The highest value of ITS in dry condition is $0.74 \mathrm{MPa}$ for RAP15 and $0.67 \mathrm{MPa}$ in wet condition for Control sample.

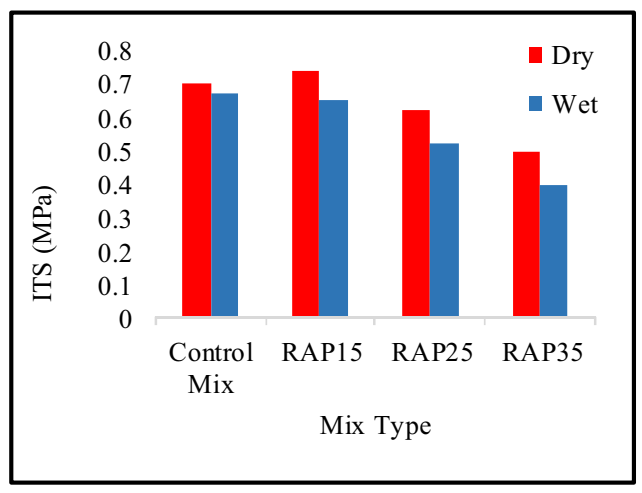

Fig. 6. Indirect Tensile Strength (ITS) for variable RAP content

The Tensile Strength Ratio (TSR) values for control mix and RAP-Asphalt mixes are shown in Fig. 7. From the results, it shows that the TSR values decreased with increasing of RAP content. The highest TSR value is $95.96 \%$ for Control mix while the lowest TSR value is $80.14 \%$ for RAP35. The results indicates that Control Mix to be less susceptible to moisture damage compared to RAP-Asphalt mixes. However, all the mixes have the potential to resist moisture damage since the TSR values obtained are more than $80 \%$. 


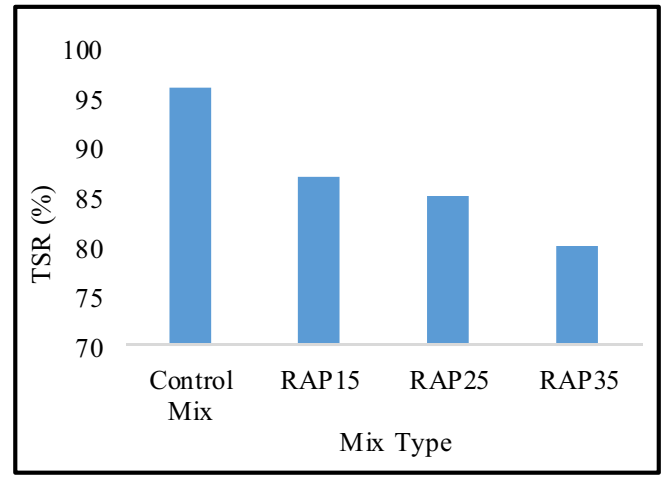

Fig. 7. Tensile Strength Ratio (TSR) for variable RAP Content

\subsection{Resilient modulus of RAP mixtures}

The results of resilient modulus test for different RAP contents at temperatures of $25{ }^{\circ} \mathrm{C}$ and $35^{\circ} \mathrm{C}$ are shown in Fig. 8. The resilient modulus for all mixes at temperature $25^{\circ} \mathrm{C}$ is higher for all mixes than at temperature of $35^{\circ} \mathrm{C}$. The results also showed that resilient modulus of the mixes decreases with increasing RAP content. The control sample has highest resilient modulus under both testing temperature compared to samples with RAP content. The resilient modulus of control sample at temperatures of $25{ }^{\circ} \mathrm{C}$ and $35{ }^{\circ} \mathrm{C}$ are $3953 \mathrm{MPa}$ and $2842 \mathrm{MPa}$ respectively. This is followed by RAP15 with values of 3784 $\mathrm{MPa}$ and $1991 \mathrm{MPa}$ at temperatures of $25^{\circ} \mathrm{C}$ and $35^{\circ} \mathrm{C}$ respectively. The results showed that RAP15 has the highest resilient modulus compared to other samples with RAP content.

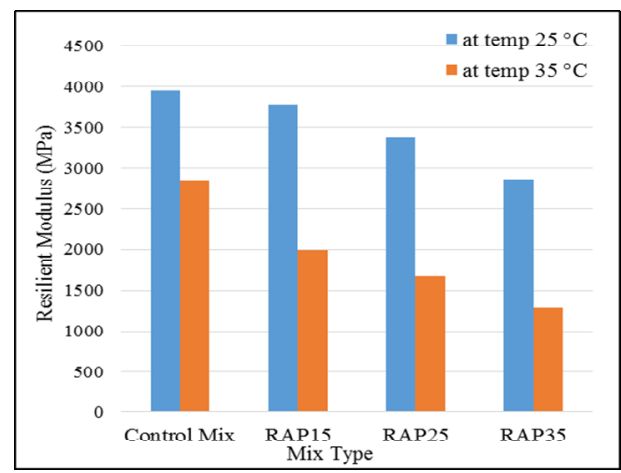

Fig. 8. Resilient modulus for variable RAP content at temperature of $25^{\circ} \mathrm{C}$ and $35^{\circ} \mathrm{C}$

Table 3 shows the percentage of resilient modulus reduction for different RAP contents at temperature $0 \mathrm{f} 25^{\circ} \mathrm{C}$ to $35^{\circ} \mathrm{C}$. The results in Table 3 show that the resilient modulus decreased significantly when the temperature increased from $25^{\circ} \mathrm{C}$ to $35^{\circ} \mathrm{C}$. The resilient modulus decreased approximately $28.12 \%$ for control mix while the resilient modulus for RAP15, RAP25 and RAP35 decreased $47.39 \%, 50.75 \%$ and $54.91 \%$ respectively. RAP35 having highest reduction of resilient modulus from temperature $25^{\circ} \mathrm{C}$ to $35^{\circ} \mathrm{C}$. This finding suggested that the percentage reduction of resilient modulus increases with increasing RAP in the mixture. 
Table 3. Percentage of reduction in resilient modulus for variable RAP content from temperature of $25^{\circ} \mathrm{C}$ to $35^{\circ}$

\begin{tabular}{|c|c|c|c|}
\hline $\begin{array}{c}\text { Mixture } \\
\text { Type }\end{array}$ & $\begin{array}{c}\text { Resilient Modulus } \\
\text { at }^{2} \mathbf{5}^{\circ} \mathbf{C}(\mathbf{M P a})\end{array}$ & $\begin{array}{c}\text { Resilient Modulus } \\
\text { at }^{\mathbf{3}} \mathbf{C} \mathbf{~ ( M P a )}\end{array}$ & $\begin{array}{c}\text { Percentage Reduction of } \\
\text { Resilient Modulus (\%) }\end{array}$ \\
\hline Control Mix & 3953.01 & 2841.59 & 28.12 \\
\hline RAP15 & 3784.09 & 1990.92 & 47.39 \\
\hline RAP25 & 3386.34 & 1667.75 & 50.75 \\
\hline RAP35 & 2858.48 & 1288.84 & 54.91 \\
\hline
\end{tabular}

\section{Conclusion}

From this study, the following can be concluded:

i. The laboratory results on the physical properties of virgin aggregate and RAP shows that the aggregates used in this study complied with the requirements in the Public Works Department specifications. The recovered aggregate from RAP has lower strength compared to virgin aggregate. This is due to the RAP material which is exposed to the environment and traffic for a certain period of time.

ii. The OBC of control mix, RAP15, RAP25 and RAP35 showed a decreasing trend with increasing RAP content. The OBC of control mix, RAP15, RAP25 and RAP35 are $5.34 \%, 5.22 \%, 5.10 \%$ and $4.8 \%$ respectively. This shows that partial blending of aged binder occurs but the effect is not as significant because of the low percentage inclusion of RAP proportion in mixes. The result indicated that use of lower percentage of RAP in mix does not significantly affect the properties of the mix.

iii. Moisture susceptibility test and resilient test were performed to evaluate the performance of recycled mixes. The ITS and TSR value of the mixture decreases as the RAP content increases under both conditions. RAP-Asphalt mixtures satisfied the minimum requirement value for the moisture susceptibility test.The resilient modulus of the RAP-Asphalt mixtures decreased with increasing RAP content and temperature.

Based on the findings of the study, it can be concluded that it is possible to design acceptable quality asphaltic concrete mixes with RAP that meets the required volumetric and desired performance criteria. As the performance of RAP mixes satisfied the minimum requirements of PWD Malaysia, the use of recycled mixes should be encouraged as the use of RAP likely to be cheaper than normal mix. The results of this study indicate that the addition of RAP to HMA is feasible as the performance is comparable to conventional asphaltic concrete mixes. The use of higher percentages of RAP content requires a detailed study and investigation to be carried out to ensure the RAP suitability and compliance with the specification requirements.

The authors would like to express gratitude to the Institute for Engineering and Sustainability Management (IIESM) and the Faculty of Civil Engineering, Universiti Teknologi MARA (UiTM) for the support given to make this study possible.

\section{References}

[1] H. Fares, K. Shahata, E. Elwakil, Modeling the performance of pavement in cold weather conditions, Structure and Infrastructure Engineering, 8(11), 1067-1079 (2010)

[2] A. Carter, Development of A Non-Solvent Based Test Method for Evaluating Reclaimed Asphalt Pavement Mixes, PhD Thesis, Auburn University, Alabama, (2004) 
[3] L. Mohammad, I. Negulescu, Z. Wu, C. Daranga, W. Daly, investigation of the use of recycled polymer modified asphalt binder in asphalt concrete pavements, Journal Associated of Asphalt Pavement Technology, 72, 551-594 (2003)

[4] B. Huang, X. Shu, D. Vukosavljevic, Laboratory investigation of cracking resistance of hot-mix asphalt field mixtures containing screened reclaimed asphalt pavement, ASCE Journal of Materials in Civil Engineering, 23(11), 1535-1543 (2011)

[5] H.R. Paul, Evaluation of recycled projects for performance, Proceedings of The Association of Asphalt Paving Technologists, 65, 231-254 (1996)

[6] W. Mengqi, W. Haifang, W. Muhunthan, N. Kalehiwot, Influence of RAP content on the air void distribution, permeability and moduli of the base layer in recycled asphalt pavements, Proceedings of the 91st Transportation Research Board Meeting, TRB (2012)

[7] C. Celauro, C. Bernardo, B. Gabriele, Production of innovative, recycled and high performance asphalt for road pavements, Journal of Resource, Conserve and Recycle, 54, 337-347 (2010)

[8] P. Shirodkar, Y. Mehta, A. Nolan, K. Sonpal, A. Norton, A study to determine the degree of partial blending of reclaimed asphalt pavement (RAP) binder for high RAP hot mix asphalt, Journal of Construction Building and Material, 25, 150-155 (2011)

[9] A.E.A. El-Maaty, A.I. Elmohr, Characterization of recycled asphalt pavement (RAP) for use in flexible pavement, American Journal of Engineering and Applied Sciences, 8(2), 233-248 (2015)

[10]K. Vislavicius, H. Sivilevicius, Effect of reclaimed asphalt pavement gradation variation on the homogeneity of recycled hot-mix asphalt, Journal of Civil and Mechanical Engineering, (2013)

[11]Public Works Department of Malaysia, Standard Specification for Road Works Section 4: Flexible Pavement (JKR/SPJ/2008-S4), Malaysia, (2008) 